\title{
Spam Filtering Methods and machine Learning Algorithm - A Survey
}

\author{
Abha Tewari \\ Student, ME \\ VESIT
}

\author{
Smita Jangale \\ Associate Professor \\ VESIT
}

\begin{abstract}
Social networking websites are used by millions of people around the world. People express their views, opinions and share current topics. Millions of data generated every day.

It's a good platform to connect with the people. Now a day's spammers used this platform to advertise spam content on the social networking websites

The proposed system used to classify tweets into different groups as spam and non spam tweets.The system will use 120 character tweets for analysis purpose. Various active and verified twitter accounts would be chosen to extract the tweets. Each tweet is to be classified into 2 category-spam and non-spam. These classified tweets then are used to train the various machine learning techniques. Words of each tweet considered as features and a feature vector was created using bag-of-words approach in order to create the instances. The data will be trained using SVM (Support Vector Machine).
\end{abstract}

\section{General Terms}

Classification, Spam Filtering methods

\section{Keywords}

Spam tweets, svm, kernel functions, SVMLIB

\section{INTRODUCTION}

There are different ways an algorithm can model a problem based on its interaction with the experience or environment or whatever we want to call the input data.

There are two general approaches to spam filtering: knowledge engineering (KE) and machine learning (ML). In the former case, a set of rules is created according to which tweets are categorized as spam or legitimate. A typical rule of this kind could look like "if the tweet contains the text BUY NOW, then the tweet is spam". A set of such rules should be created either by the user of the filter, or by some other authority (e.g.

The software company that provides a particular rule-based spam-filtering tool). [2]

The paper is organized as follows. The section 2 presents a machine learning algorithm, different types of machine learning algorithm Section 3 explains spam filtering methods, Section 4 elaborates Classification of tweets, Section 5 explains support vector machine (SVM), kernel functions. Here will analyze one small dataset. Section 6 offers conclusions and directions for future work.

\section{MACHINE LEARNING ALGORITHM}

"Machine Learning is the field of study that gives computers the ability to learn without being explicitly programmed."

The data set is trained in such a way that the predefined output always come whenever applying machine learning algorithm.

\subsection{Different types of Machine Learning Algorithm}

Two most important learning styles are supervised and unsupervised learning [4]:

Supervised Learning: Labeled and classified data are used to train the model. The training process predicts the output; if it not matches the actual output then process is repeated again until the actual output comes. Sometimes it is also called intelligent learning model.

Working: This algorithm consists of a target variable which is to be predicted from a given set of predictors (independent variables). Using these set of variables, it generate a function that map inputs to desired outputs. The training process continues until the desired output is not obtained.

Examples of Supervised Learning: Regression, Decision Tree, Random Forest, KNN, Logistic Regression, back propagation neural network etc.

Unsupervised Learning: The training process is done on unlabelled /not classified data. The model is to be trained for the unknown output. It requires deep understanding of mathematical concepts.

Working: In this algorithm, do not have any target or outcome variable to predict / estimate. It is used for clustering population in different groups, which is widely used for segmenting customers in different groups for specific intervention. Example problems are clustering, dimensionality reduction and association rule learning. Example algorithms include: the Apriori algorithm and k-Means.

\subsection{Applications of Machine Learning Algorithm[5]}

Machine learning algorithms are being used in lots of places in interesting ways. Some applications are

\subsubsection{Face detection}

The face detection Feature in mobile cameras is an example of what machine learning can do. Cameras can automatically snap a photo when someone smiles more accurately now than ever before because of advances in machine learning algorithms.

\subsubsection{Face recognition}

This is where a computer program can identify an individual from a photo. You can find this feature on Facebook for automatically tagging people in photos where they appear. Advances in machine learning mean more accurate auto-face tagging soft wares. 


\subsubsection{Image classification:}

A good example is the application of deep learning to improve image classification or image categorization in apps such as Google photos. Google photos would not be possible without advances in deep learning.

\subsubsection{Speech recognition}

Another good example is Google now. Improvements in speech recognition systems has been made possible by, you guessed right, machine learning specifically deep learning.

\subsubsection{Google}

Google defines itself as a machine learning company now. It is also a leader in this area because machine learning is a very important component to its core advertising and search businesses. It applies machine learning to improve search results and search suggestions.

\subsubsection{Anti-virus}

Machine learning is used in Anti-virus software's to improve detection of malicious software on computer devices.

\subsubsection{Anti-spam:}

machine learning is also used to train better anti-spam software systems.

\subsubsection{Genetics:}

Classical data mining or clustering algorithms in machine learning such as agglomerative clustering algorithms are used in genetics to help find genes associated with a particular disease.

\subsubsection{Signal denoising:}

Machine learning algorithms such as the K-SVD which is just a generalization of k-means clustering are used to find a dictionary of vectors that can be sparsely linearly combined to approximate any given input signal. Thus such a technique is used in video compression and denoising.

\subsubsection{Weather forecast:}

Machine learning is applied in weather forecasting software to improve the quality of the forecast.

Machine learning makes it relatively easier to develop sophisticated software systems without much effort on the human side. Instead of spending years handcrafting features or fine tuning a system with a lot of parameters, machine learning does that quicker. It also only requires training data to learn better features or parameters needed to improve a given system.

\section{SPAM FILTERING METHDS}

Different techniques have been used by researchers to find out the spam content. Table 1 is showing the summary of the different methods with their advantages and disadvantages. [3]
Table 1 Different spam filtering methods

\begin{tabular}{|c|c|c|c|}
\hline $\begin{array}{l}\text { List-Based } \\
\text { Filters }\end{array}$ & & Advantages & Disadvantages \\
\hline & Blacklist & $\begin{array}{l}\text { Attempts to } \\
\text { stop unwanted } \\
\text { email by } \\
\text { blocking } \\
\text { messages } \\
\text { from a preset } \\
\text { list of senders. }\end{array}$ & $\begin{array}{l}\text { Misidentify } \\
\text { legitimate } \\
\text { senders as } \\
\text { spammers. }\end{array}$ \\
\hline & $\begin{array}{l}\text { Real-Time } \\
\text { Black hole } \\
\text { List }\end{array}$ & $\begin{array}{l}\text { (i) Identically } \\
\text { to a traditional } \\
\text { blacklist. } \\
\text { (ii)Real-time } \\
\text { black hole } \\
\text { lists are } \\
\text { maintained by } \\
\text { third parties }\end{array}$ & $\begin{array}{l}\text { (i)Can also } \\
\text { generate false } \\
\text { positives if } \\
\text { spammers } \\
\text { happen to use } \\
\text { a legitimate IP } \\
\text { address as a } \\
\text { conduit for } \\
\text { junk mail. } \\
\text { (ii)Less } \\
\text { control over } \\
\text { what addresses } \\
\text { are on - or } \\
\text { not on - the } \\
\text { list. }\end{array}$ \\
\hline & White list & $\begin{array}{l}\text { White list lets } \\
\text { specify which } \\
\text { senders to } \\
\text { allow mail } \\
\text { from; these } \\
\text { addresses are } \\
\text { placed on a } \\
\text { trusted-users } \\
\text { list. }\end{array}$ & $\begin{array}{l}\text { Very strict } \\
\text { filter that only } \\
\text { uses a white } \\
\text { list would } \\
\text { mean that } \\
\text { anyone who } \\
\text { was not } \\
\text { approved } \\
\text { would } \\
\text { automatically } \\
\text { be blocked. }\end{array}$ \\
\hline & Grey list & $\begin{array}{l}\text { The receiving } \\
\text { mail server } \\
\text { initially } \\
\text { rejects } \\
\text { messages } \\
\text { from } \\
\text { unknown } \\
\text { users and } \\
\text { sends a failure } \\
\text { message to the } \\
\text { originating } \\
\text { server. } \\
\text { If the mail } \\
\text { server }\end{array}$ & $\begin{array}{l}\text { They may } \\
\text { delay mail } \\
\text { delivery, } \\
\text { which could } \\
\text { be } \\
\text { inconvenient } \\
\text { when you are } \\
\text { expecting } \\
\text { time-sensitive } \\
\text { messages. }\end{array}$ \\
\hline
\end{tabular}




\begin{tabular}{|c|c|c|c|}
\hline & & $\begin{array}{l}\text { attempts to } \\
\text { send the } \\
\text { message a } \\
\text { second time } \\
\text { — a step most } \\
\text { legitimate } \\
\text { servers will } \\
\text { take - the } \\
\text { grey list } \\
\text { assumes the } \\
\text { message is not } \\
\text { spam and lets } \\
\text { it proceed to } \\
\text { the recipient's } \\
\text { inbox. At this } \\
\text { point, the grey } \\
\text { list filter will } \\
\text { add the } \\
\text { recipient's } \\
\text { email or IP } \\
\text { address to a } \\
\text { list of allowed } \\
\text { senders. }\end{array}$ & \\
\hline \multirow[t]{3}{*}{$\begin{array}{l}\text { Content- } \\
\text { Based } \\
\text { Filters }\end{array}$} & $\begin{array}{l}\text { Word- } \\
\text { Based } \\
\text { Filters }\end{array}$ & $\begin{array}{l}\text { Configured to } \\
\text { block } \\
\text { messages } \\
\text { containing } \\
\text { more common } \\
\text { words }\end{array}$ & $\begin{array}{l}\text { IT staff will } \\
\text { need to make } \\
\text { time to } \\
\text { routinely } \\
\text { update the } \\
\text { filter's list of } \\
\text { blocked } \\
\text { words. }\end{array}$ \\
\hline & $\begin{array}{l}\text { Heuristic } \\
\text { Filters }\end{array}$ & $\begin{array}{l}\text { Rather than } \\
\text { blocking } \\
\text { messages that } \\
\text { contain a } \\
\text { suspicious } \\
\text { word, } \\
\text { heuristic } \\
\text { filters take } \\
\text { multiple terms } \\
\text { found in an } \\
\text { email into } \\
\text { consideration. }\end{array}$ & $\begin{array}{l}\text { Configured to } \\
\text { be aggressive } \\
\text { may generate } \\
\text { false positives } \\
\text { if a legitimate } \\
\text { contact } \\
\text { happens to } \\
\text { send an email } \\
\text { containing a } \\
\text { certain } \\
\text { combination } \\
\text { of words. }\end{array}$ \\
\hline & $\begin{array}{l}\text { Bayesian } \\
\text { Filters }\end{array}$ & $\begin{array}{l}\text { Employ the } \\
\text { laws of } \\
\text { mathematical } \\
\text { probability to } \\
\text { determine } \\
\text { which } \\
\text { messages are } \\
\text { legitimate and } \\
\text { which are } \\
\text { spam. }\end{array}$ & $\begin{array}{l}\text { However, } \\
\text { since this } \\
\text { method does } \\
\text { require a } \\
\text { training period } \\
\text { before it starts } \\
\text { working well, } \\
\text { you will need } \\
\text { to exercise } \\
\text { patience and } \\
\text { will probably } \\
\text { have to }\end{array}$ \\
\hline
\end{tabular}

\begin{tabular}{|c|c|c|c|}
\hline & & & $\begin{array}{l}\text { manually } \\
\text { delete a few } \\
\text { junk messages, } \\
\text { at least at first. }\end{array}$ \\
\hline $\begin{array}{l}\text { Other } \\
\text { Filtering } \\
\text { Methods }\end{array}$ & $\begin{array}{l}\text { Challenge/ } \\
\text { Response } \\
\text { System }\end{array}$ & $\begin{array}{l}\text { Filters that use } \\
\text { a } \\
\text { challenge/resp } \\
\text { onse system } \\
\text { block } \\
\text { undesirable } \\
\text { emails by } \\
\text { forcing the } \\
\text { sender to } \\
\text { perform a task } \\
\text { before their } \\
\text { message can } \\
\text { be delivered. }\end{array}$ & $\begin{array}{l}\text { Challenge/resp } \\
\text { onse filters } \\
\text { might block } \\
\text { email } \\
\text { newsletters } \\
\text { you subscribe } \\
\text { to, as these } \\
\text { messages are } \\
\text { typically sent } \\
\text { by automated } \\
\text { programs }\end{array}$ \\
\hline & $\begin{array}{l}\text { Collabora } \\
\text { tive } \\
\text { Filters }\end{array}$ & $\begin{array}{l}\text { Collaborative } \\
\text { content } \\
\text { filtering takes } \\
\text { a community- } \\
\text { based } \\
\text { approach to } \\
\text { fighting spam } \\
\text { by collecting } \\
\text { input from the } \\
\text { millions of } \\
\text { email users } \\
\text { around the } \\
\text { globe }\end{array}$ & $\begin{array}{l}\text { If a group of } \\
\text { spammers } \\
\text { mobilize in } \\
\text { large numbers } \\
\text { and pretend to } \\
\text { be legitimate } \\
\text { users of the } \\
\text { system, they } \\
\text { could skew } \\
\text { results by } \\
\text { falsely } \\
\text { labeling spam } \\
\text { emails as } \\
\text { legitimate } \\
\text { messages. }\end{array}$ \\
\hline & $\begin{array}{l}\text { DNS } \\
\text { Lookup } \\
\text { Systems }\end{array}$ & $\begin{array}{l}\text { Attempts to } \\
\text { verify that the } \\
\text { domain name } \\
\text { in the email } \\
\text { address of the } \\
\text { sender — the } \\
\text { part after the } \\
\text { at symbol (@) } \\
\text { — exists. }\end{array}$ & $\begin{array}{l}\text { Reverse DNS } \\
\text { lookups have } \\
\text { been known to } \\
\text { produce false } \\
\text { positives - } \\
\text { legitimate } \\
\text { messages } \\
\text { marked as } \\
\text { spam }\end{array}$ \\
\hline
\end{tabular}

\section{CLASSIFICATION of TWEETS}

There are five main types of Tweets that is posted by people [6]: 


\subsection{Links}

Posting links to good info or maybe posting a quote you like. The aim of these is to get them shared by others.

\subsection{Images}

To post a photo or GIF in a Tweet on Twitter

\subsection{Quotes}

The famous quotes and saying about life, love, friendship, philosophy and more.

\subsection{Retweets}

Sharing good tweets from others

\subsection{Questions or comments of your own 4.6 Spam Tweets}

Unfortunately Twitter is not immune to spam. In fact, spam happens on a regular basis with people often using the "@..." function to directly sell a product or service. This is poor practice.

\section{MACHINE LEARNING ALGORITHM-SVM}

The Support Vector Machine is one of the most modern techniques used in mail classification. In abstract view, it is a kernel machine with the strong mathematical base. It is a technique of pattern recognition and data analysis. The training sample is a set of vectors of $n$ attributes. At the end of training phase, we can say that, we are in hyperspace having dimensions equal to the number attributes. In process of spam filtering, SVM Builds hyperspace with two classes, namely, spam and ham. These two classes are separated by a hyper plane. Every mail instance is treated as a single point with $n$ dimensions in hyperspace. The distance between the hyper planes and points of each class, is kept maximum, for good separation. [1]

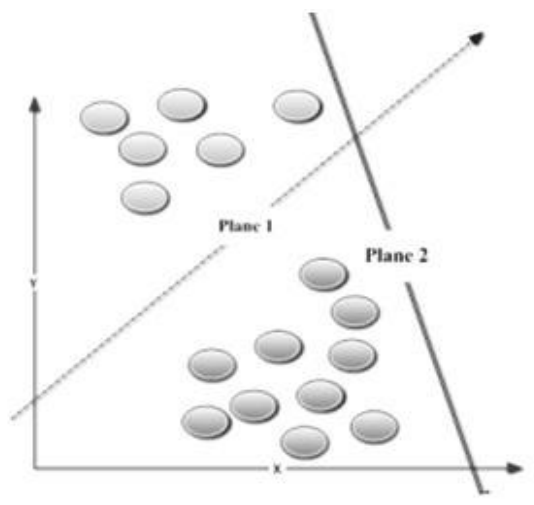

Fig.1: Hyper plane that separate the two classes

Plane1 is good classifier and Plane2 doesn't classify all instances. It may also happen that, the plane can't find good separator hyper plane (Plane 1) as in fig.1. In such case, hyperspace is called as non-linearly separable. To obtain linear separation in the non-linearly separable hyperspace, it is extended to more dimensions.

\subsection{Kernel Functions}

It gives the equivalent of mapping a nonlinear separable input space, to a higher dimensional feature space that is linearly separable. [1]

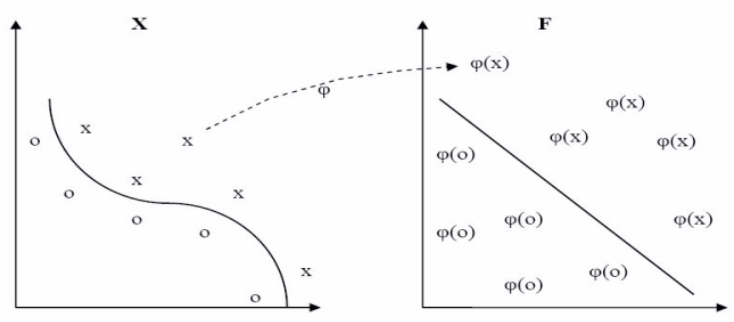

Fig 2: Mapping of kernel functions

The four types of kernel functions frequently used with SVM:

1. Linear

2. Polynomial

3. RBF

4. Sigmoid

There is no specific technique to detect which kernel is best for a particular problem.

\subsection{LIBSVM: A Library for Support Vector Machines}

Case study: Here analyzed svm using one small dataset. In R tool. The selection of kernel functions in the svm function parameters gives different output.

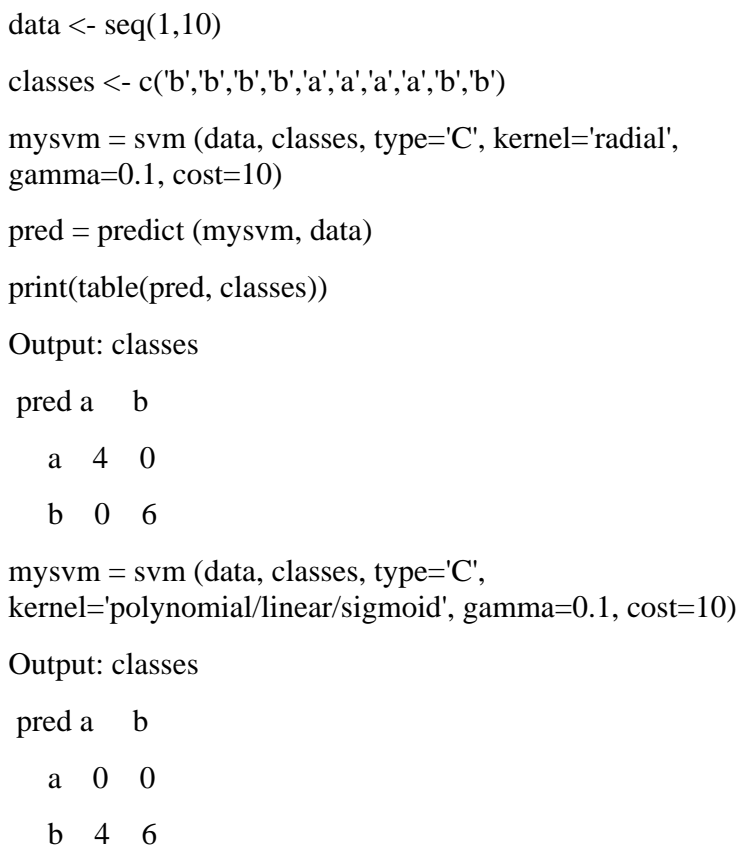

mysvm $=$ svm $\left(\right.$ data, classes, type $={ }^{\prime} \mathrm{C}^{\prime}$,

kernel='polynomial/linear/sigmoid', gamma $=0.1$, cost $=10$ )

Output: classes

pred a $b$

a $\quad 0 \quad 0$

b $4 \quad 6$

So the choice of kernel function plays a very important role in SVM machine learning algorithm.

\section{CONCLUSION}

In this paper we explained about machine learning algorithm, different spam filtering methods and implementation of SVM in the case study in the section 5.2 done on $\mathrm{R}$. The project envisions two directions towards which the work can evolve. Future work would be planning to classify tweets based on spam vs. ham (legitimate tweets). The work would explore the SVM with different parameters and comparing SVM with 
other classifier algorithm.. Finally, aim at investigating other kinds of machine learning algorithm for spam filtering

\section{ACKNOWLEDGMENT}

It gives immense pleasure to express my deep and sincere gratitude to my project guide Prof. Mrs.Smita Janjale for her kind help and valuable advice during the study and for her guidance and suggestions.

\section{REFERENCES}

[1] "Dynamic Feature Selection for Spam Filtering Using Support Vector Machine" by Md. Rafiqul Islam, Wanlei Zhou and Morshed U. Choudhury

[2] "Machine Learning Techniques in Spam Filtering" Konstantin Tretyakov,kt@ut.ee Institute of Computer Science, University of Tartu Data Mining Problem oriented Seminar, MTAT.03.177,

[3] http://www.techsoup.org/learningcenter/internet/page602 8.cfm
[4] http://machinelearningmastery.com/a-tour-of-machinelearning-algorithms/ "A Tour of Machine Learning Algorithms by Jason Brownlee on November 25, 2013 in Machine Learning Algorithms

[5] https://www.quora.com/What-are-some-interestingpossible-applications-of-machine-learning

[6] "A Performance Evaluation of Machine Learning-Based Streaming Spam Tweets Detection" Chao Chen, Jun Zhang, Member, IEEE, Yi Xie, Yang Senior Member, IEEE,@2015

[7] https://blog.bufferapp.com/the-5-types-of-tweets-tokeep-your-buffer-full-and-your-followers-engaged

[8] "Spam Filtering Techniques and MapReduce with SVM: A Study" by Amol G. Kakade, Prashant K. Kharat, Anil Kumar Gupta,Tarun Batra @2014 IEEE 